\title{
The application of models to find the relevance of residence time in lake and reservoir management
}

\author{
Sven E. JØRGENSEN \\ DFH, Environmental Chemistry, University Park 2, 2100 Copenhagen Ø, Denmark \\ e-mail: sej@dfh.dk
}

\begin{abstract}
The residence time is among the most important factors that determine the water quality of lakes and reservoirs. Models are useful tools to reveal the relationship between the residence time and the water quality. Three case studies are presented to illustrate the application of models to determine the importance of the residence time for the water quality. It was found that manipulation of the residence time, i.e. ecohydrology, may be a very useful environmental management tool.
\end{abstract}

Key words: residence time, modelling, structural dynamics, ecohydrology

\section{INTRODUCTION}

The residence time is together with the concentrations of various chemical compounds in the inflowing water among the most important factors that determine the water quality in lakes and reservoirs. Today we have experience with application of a wide spectrum of lake and reservoir models in environmental management. It is therefore naturally to apply the developed models to ask the very relevant questions in environmental management: "What is the role of the residence time in determination of the water quality? Would it be possible to manipulate the residence time to improve the water quality?"

This paper attempts to answer these two pertinent questions in three concrete cases by the use of eutrophication models:

1) Lake Fure situated between 13 and $19 \mathrm{~km}$ from the center of Copenhagen was in the sixties and early seventies exposed to an increasing eutrophication. The lake has in many years received mechanicalbiological treated waste water. It was therefore decided in 1972 to solve the problems by i) deviation of the wastewater from about 50,000 inhabitants to the sea (Øresund), ii) treating the waste water from another 20,000 inhabitants by a chemical precipitation before the primary settling tank using iron(III) chloride and after the secondary settling using aluminium sulfate, yielding a total phosphorus removal efficiency of more than $98 \%$. By the deviation of the waste water was the hydraulic residence time increased from about 16-17 years to about 21-22 years.

2) The wastewater previously discharged to Lake Glum situated about $80 \mathrm{~km}$ south of Copenhagen was in 1982 deviated to down-streams the lake. The lake has an area of about $500,000 \mathrm{~m}^{2}$ and the mean depth is $1.8 \mathrm{~m}$. It was after the deviation of the waste water considered to recover the lake faster by pumping ground water to the lake to reduce the residence time from 6 months to 4 months.

3) It was found in a Polish drinking water reservoir that it was possible to reduce the eutrophication by reducing the hydraulic residence time during the months from 1st of April to 1st of August (Jørgensen 2001).

\section{THE APPLIED MODELS}

The conceptual diagram for the model applied for the cases 1 and 2 described above is shown in figure 1 . The figure shows the nitrogen cycle of the model, but similar nutrient cycles are applied for carbon and phosphorus with the difference that these two nutrients only exist in one inorganic form respectively hydrogen carbonate and hydrogen phosphate. Figure 2 shows the exchange processes between sediment of water that included in the model. The model has as seen a detailed description of these exchange processes. The nutrient content of the settled phytoplankton and detritus is divided in exchangeable nutrients and non-exchangeable nutrient. The exchangeable nutrient is mineralized and form inorganic nutrient in the pore water of the sediment. The nutrients in the pore water is transferred to the lake water by diffusion. The model is rather complex with independent cycles of the three nutrient carbon, nitrogen and phosphorus in addition to the detailed sediment water exchange submodel. A detailed description of the model is given in Jørgensen \& Bendoricchio (2001) and in Jørgensen et al. (1978).

Figure 3 shows the model applied for the Polish reservoir. The STELLA diagram is shown and the equations on the STELLA-form are summarized in Appendix 1. Only the phosphorus cycle is included in the model, as phosphorus is the limiting nutrient. The model 


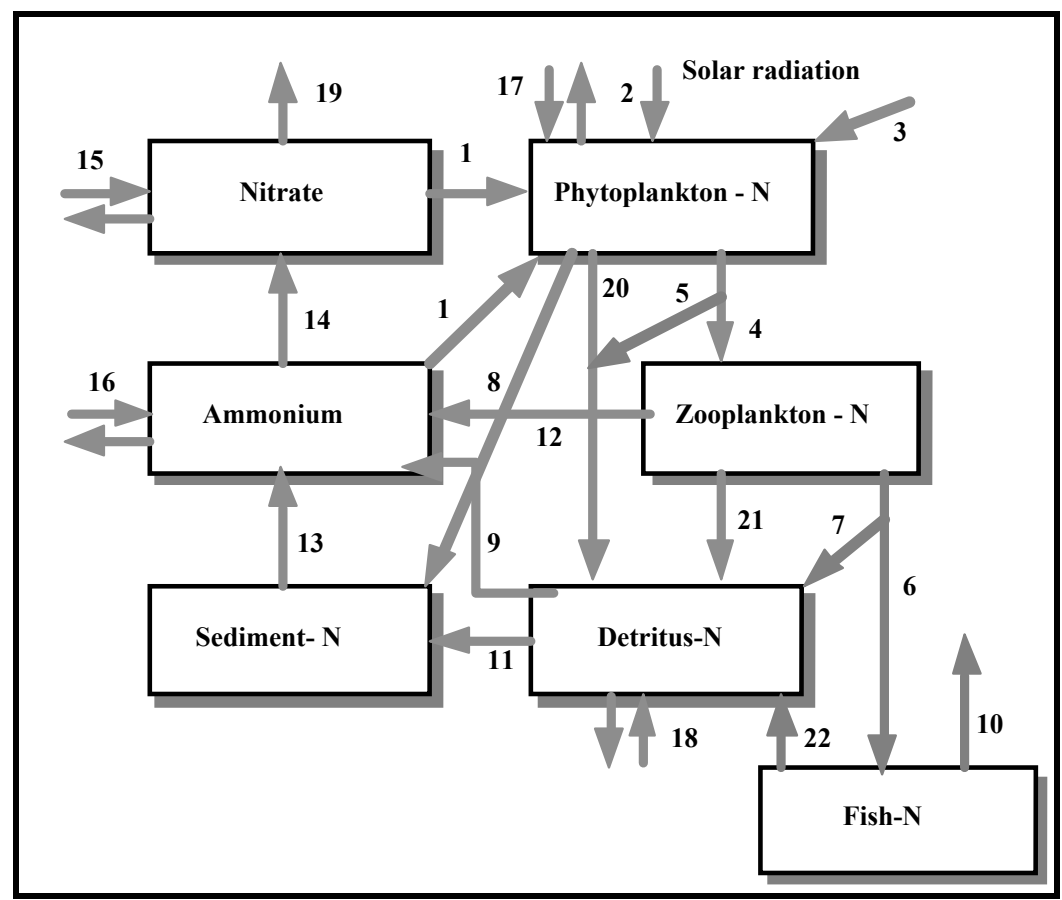

Fig. 1. The conceptual diagram for the model applied in cases 1 and 2 . The nitrogen cycle is shown and a similar description is applied for the phosphorus and carbon cycle. The model is based on independent cycling of the three elements with the possibilities of phytoplankton to contain $5-12 \%$ nitrogen, $40-60 \%$ carbon and $0.4-2.5 \%$ phosphorus.

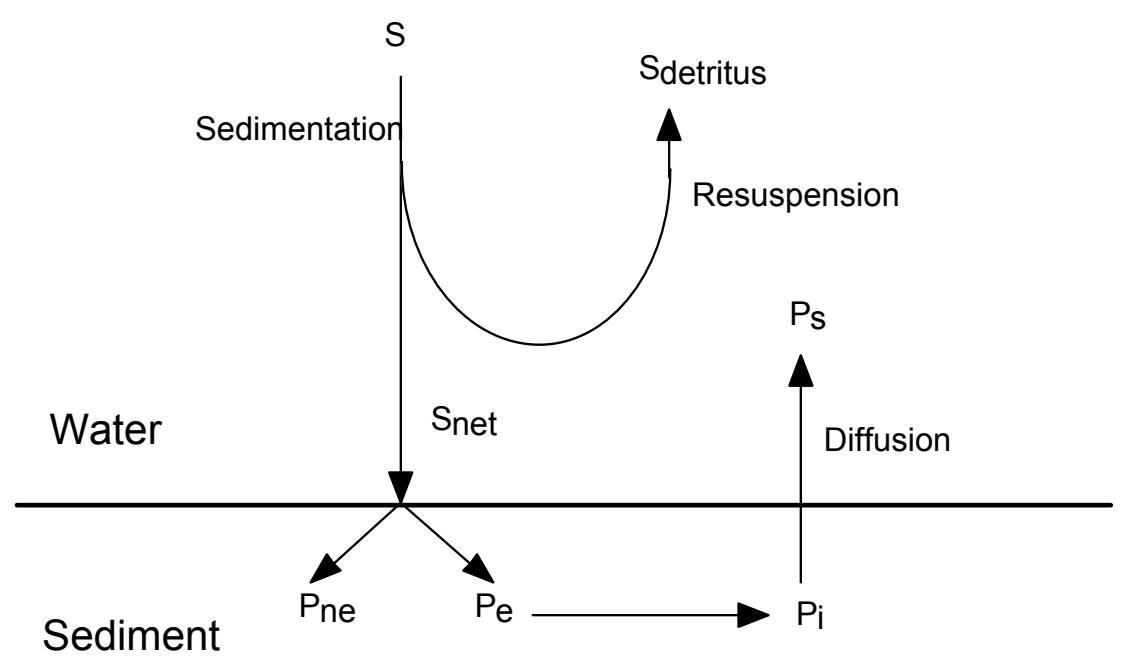

Fig. 2. The description of the sediment water exchange is shown. The settled nitrogen and phosphorus may either be nonexchangeable or exchangeable. The exchangeable part mineralizes and dissolves in the pore water. The nutrients in the pore water are transferred to the lake water by diffusion.

has 11 state varaibles: the volume, inorganic phosphorus, PS, phosphorus in form of phytoplankton, PA, phosphorus in form of zooplankton, $\mathrm{PZ}$, phosphorus in form of planktivorous fish, PPF, phosphorus in form of carnivorous fish, PCF, detritus phosphorus, PD, phosphorus in the sediment, PSED, phosphorus in the pore water, PPW, phosphorus in the planktivorous fish eggs, PEPF, and phosphorus in the carnivorous fish eggs, PETP. The two last state variables are included to account for an observed effect of the water level on the efficiency of spawning for the two fish groups. When the water level is low the most attractive, the sandy spawning areas close to the shorelines preferred by the fish are not any longer under water which inevitably reduces the spawning efficiency. A shorter retention time in the period April to August has therefore two effects, that the model tries to capture: 1) faster wash out of the nutrients reducing the eutrophication 2) the number of particularly planktivorous fish is reduced, which implies reduced predation on zooplankton. The model is therefore developed to quantify the result of this ecohydrological measure. 


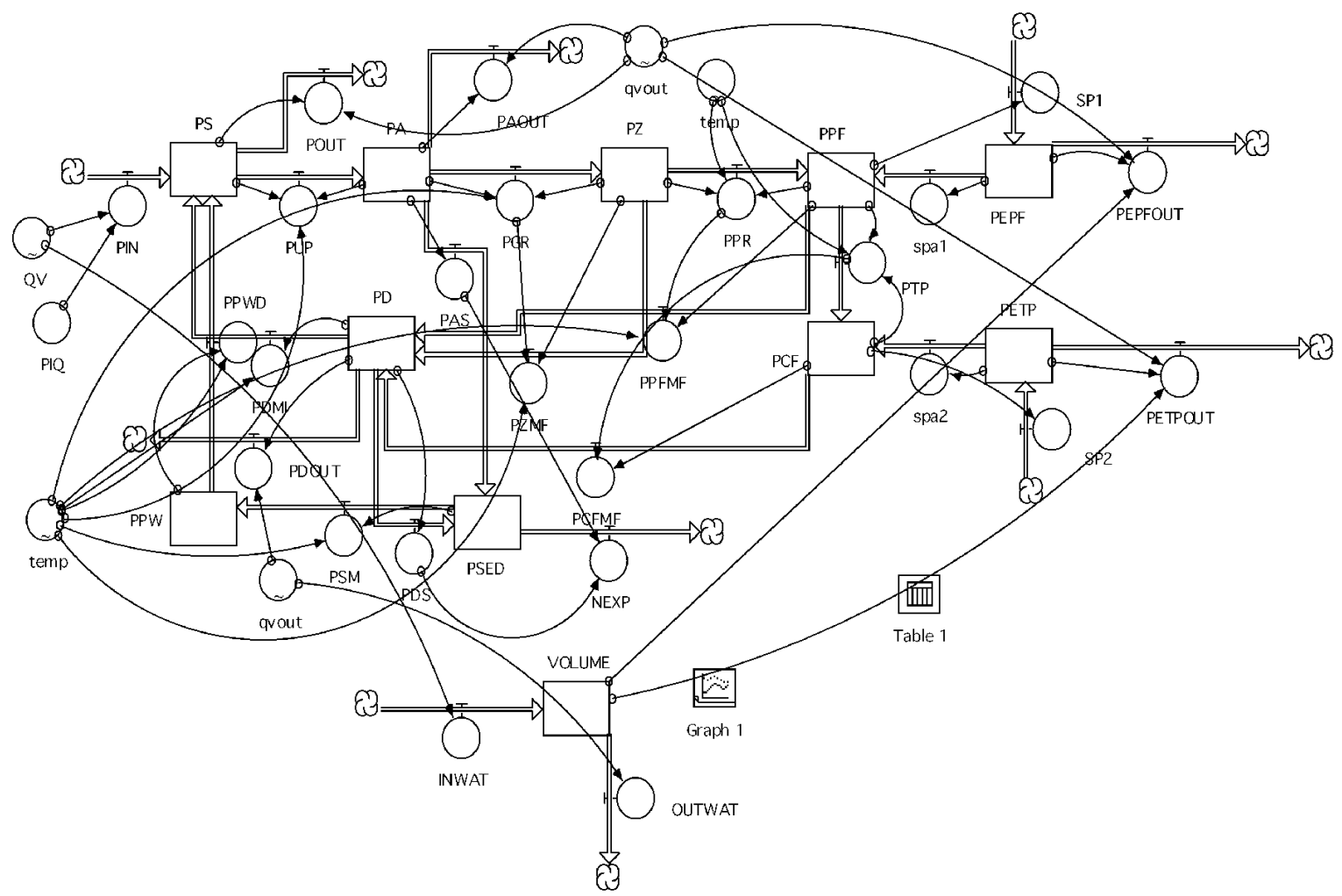

Fig. 3. A STELLA diagram of the model applied in case study three. The boxes are the state variables, the fat arrows are processes and the thin arrows indicate the controls. The model has 11 state varaibels: the volume, inorganic phosphorus, PS, phosphorus in form of phytoplankton, PA, phosphorus in form of zooplankton, PZ, phosphorus in form of planktivorous fish, PPF, phosphorus in form of carnivorous fish, PCF, detritus phosphorus, PD, phosphorus in the sediment, PSED, phosphorus in the pore water, PPW, phosphorus in the planktivorous fish eggs, PEPF, and phosphorus in the carnivorous fish eggs, PETP.

\section{RESULTS}

The described model was applied for Lake Fure when the decision to deviate a part of the wastewater and treat very effectively another part of the wastewater was taken in 1972. The model version has two layer cooresponding to formation of a thermocline from MayOctober. It was very clear that a shorter retention time would influence the restoration rate of the water quality. The transparency would according to the model increases from about $1.2 \mathrm{~m}$ in 1972 to about $2.0 \mathrm{~m}$ in 1995 when it was minimum during the spring and summer bloom provided that all the wastewater would be treated very effectively, while a deviation of the wastewater for 50,000 inhabitants would imply that the minimum transparency in the mid nineties would be $1.8 \mathrm{~m}$ only. The minimum transparency was measured to be $1.85 \mathrm{~m}$ in May 95. The model explains why the recovery is going very slowly. The internal loading in the mid nineties was calculated to be about 12 tons of phosphorus while the external loading that year only was about $2.5 \mathrm{t}$. The main external source was storm-water overflows. It is under discussion to restore the lake by aeration of the hypolimnion which would reduce the internal loading as the hypolimnion during the summer still is anaerobic. Aerobic conditions in hypolimnion would ensure that iron was in form of iron(III) ions which has a high binding capacity for phosphate as the very insoluble iron(III) phosphate. A reduction of the phosphorus loading from the storm-water by chemical precipation has also been discussed.

The same model but of course without thermocline has been applied to assess that a reduction of the residence time for Lake Glum from 6 months to 4 months would result in an about $25 \%$ reduction of the primary production three years later. The minimum transparency would according to the model increases from $18 \mathrm{~cm}$ to $70 \mathrm{~cm}$ against a transparency of $50 \mathrm{~cm}$ when the normal residence time of 6 months applies. Unfortunately, the faster recovery by the use of ground water was never realized. The observed minimum transparency was close to $50 \mathrm{~cm}$ the third year which could be considered a clear confirmation of the model results.

Table 1 shows the results of the model figure 3 . The model has been applied to compare the four trophic levels phytoplankton, zooplankton, planktivorous fish and carnivorous fish, when the outflow in the months April, May, June and July was twice the outflow in the remaining 8 months and when the outflow was constant 
Tab. 1. Quantification of ecohydrological effect on biological components.

\begin{tabular}{lcccccc}
\hline & \multirow{2}{*}{$\begin{array}{c}\text { P in-flow } \\
\text { Component }\end{array}$} & \multicolumn{5}{c}{ Spring and summer peaks (mg P 1 $\left.{ }^{-1}\right)$} \\
\cline { 3 - 6 } & $\left(\mathrm{mg} \mathrm{l}^{-1}\right)$ & Constant out-flow rate & High out-flow rate 1/4-1/8 & Difference \\
\hline Phytoplankton & 1.0 & 0.98 & 1.02 & 0.67 & 0.77 & down $28 \%$ \\
Phytoplankton & 0.5 & 0.76 & 0.70 & 0.40 & 0.42 & down $44 \%$ \\
Phytoplankton & 0.2 & 0.44 & 0.42 & 0.32 & 0.40 & down $44 \%$ \\
Phytoplankton & 0.05 & 0.32 & 0.32 & 0.16 & 0.16 & down $50 \%$ \\
Zooplankton & 1.0 & 0.02 & 0.54 & 0.17 & 0.19 & up 29\% \\
Zooplankton & 0.5 & 0.02 & 0.38 & 0.21 & 0.23 & up $10 \%$ \\
Zooplnakton & 0.2 & 0.02 & 0.30 & 0.04 & 0.18 & down $31 \%$ \\
Zooplankton & 0.05 & 0.02 & 0.28 & 0.04 & 0.16 & down $33 \%$ \\
Planktivorous fish & 1.0 & 2.50 & 1.90 & 1.10 & 1.60 & down $39 \%$ \\
Planktivorous fish & 0.5 & 2.30 & 1.50 & 1.01 & 1.19 & down $42 \%$ \\
Planktivorous fish & 0.2 & 1.15 & 1.01 & 0.50 & 0.72 & down $44 \%$ \\
Planktivorous fish & 0.05 & 0.70 & 0.70 & 0.33 & 0.48 & down $42 \%$ \\
Carnivorous fish & 1.0 & 0.62 & & 0.53 & down $15 \%$ \\
Carnivorous fish & 0.5 & 0.60 & & 0.52 & down $13 \%$ \\
Carnivorous fish & 0.2 & 0.58 & & 0.50 & down $14 \%$ \\
Carnivorous fish & 0.05 & 0.56 & & 0.49 & down $12.5 \%$ \\
\hline
\end{tabular}

over the year. The total annual outflow was of course the same in the two cases. The eutrophication was clearly reduced by the application of the higher outflow in the months when the phytoplankton bloom and fish spawning should be expected. These results are consistent with observations from the Polish reservoir (Zalewski \& Wagner 2000).

\section{CONCLUSIONS}

Models have been applied in this study to assess the role of the residence time for determination of the water quality. It is possible to conclude from the presented three case studies that a model is a very useful instrument for determination of the role of the residence time in environmental management. It has been demonstrated that the residence time is an important forcing function that in many cases will have a great influence on the resulting water quality of a lake and reservoir.

The second question raised in the introduction: Would it be possible to manipulate the residence time to improve the water quality? Can be answered by "yes", as a significant reduction in the eutrophication level was obtained according to the model results that were confirmed by observations. As the model is very general and the effects are causal, it seems possible to conclude that the here obtained results should be expected also for many other lake and reservoir studies. It can therefore be recommended to apply models to estimate the results of the proposed ecohydrological method: to manipulate the residence time to obtain an improved water quality.

\section{REFERENCES}

Jørgensen, S.E. 2001. Ecological Models are useful tools in ecohydrology. Ecohydrology \& Hydrobiology, 1: 283-290. Jørgensen, S.E. \& G. Bendoricchio. 2001. Fundamentals of Ecological Modelling. Elsevier, Amsterdam: 528 pp.

Jørgensen, S.E, H.F. Mejer \& L.A. Jørgensen. 1978. Examination of a Lake Model. Ecological Modelling, 4: 253278.

Zalewski, M. \& I. Wagner. 2000. Ecohydrology. Technical Document in Hydrology, 34. UNESCO, Paris.

\section{Appendix 1}

\section{EQUATIONS}

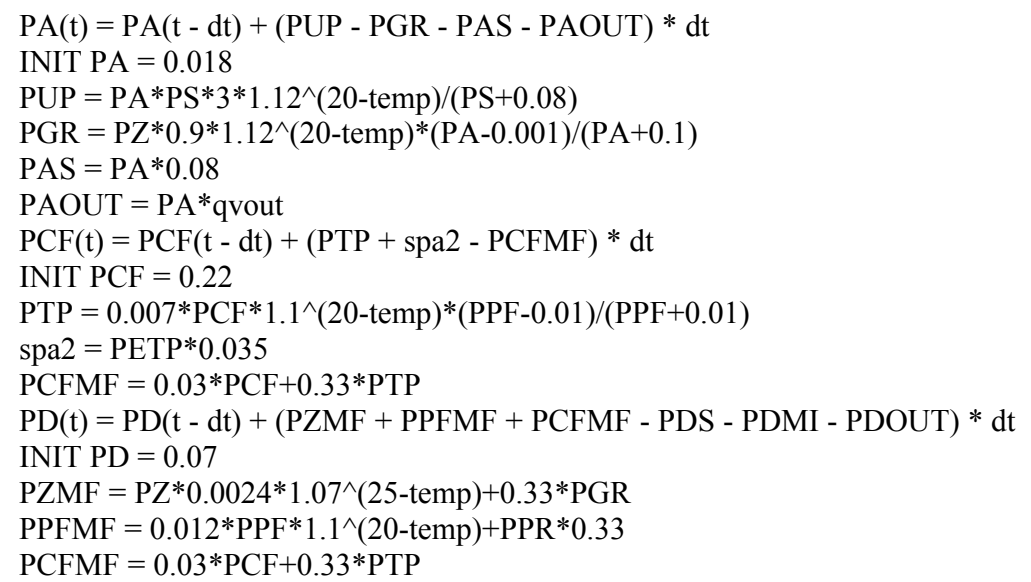




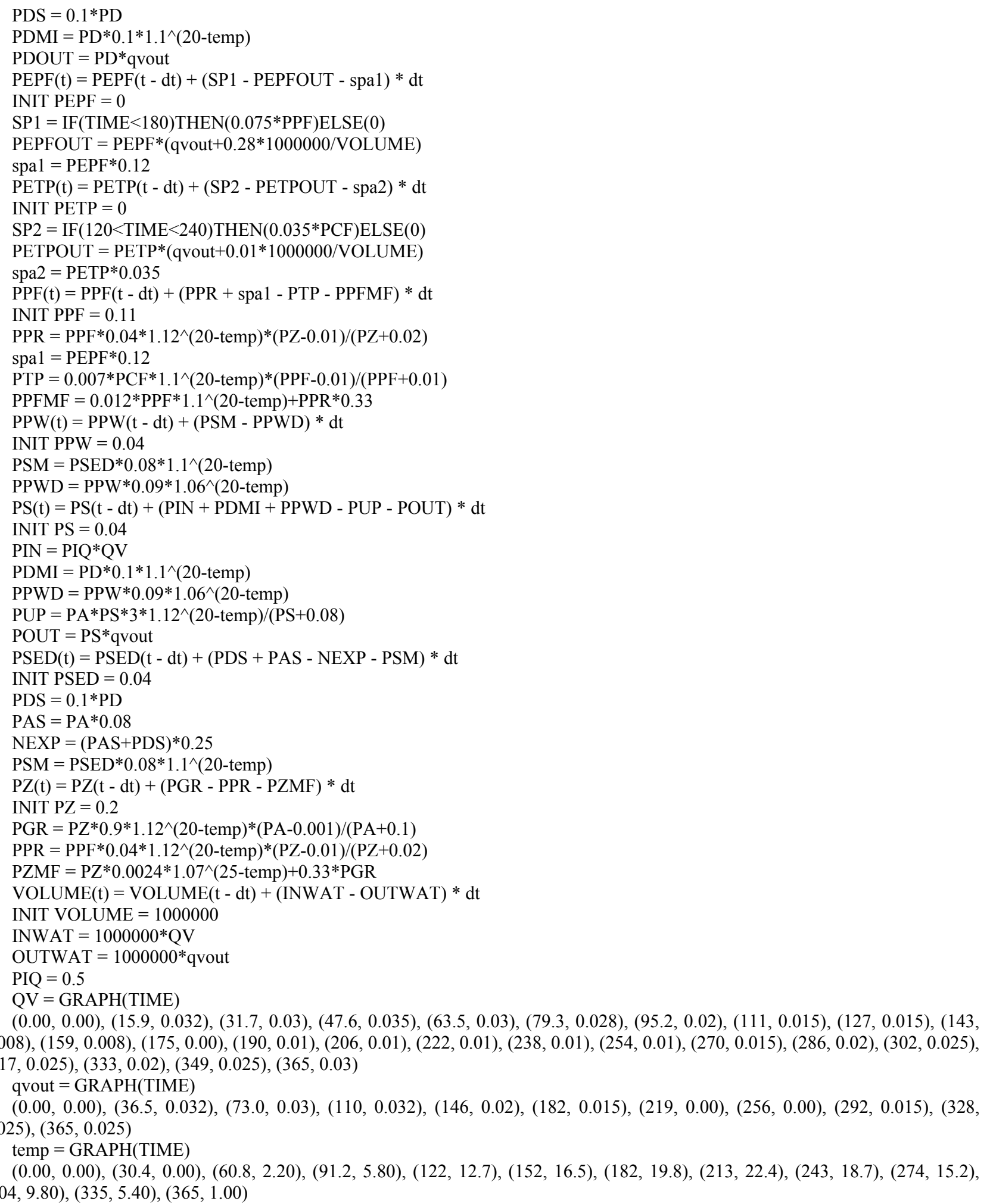
$(304,9.80),(335,5.40),(365,1.00)$ 